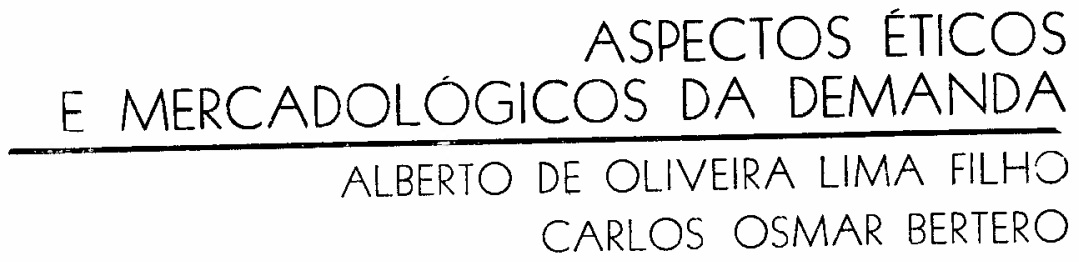

"De modo geral é impossível para o homem ser tão plenamente racional, informado e capaz de prever tôdas as conseqüências de suas açõas e dias ações dos outros homens para o bem-estar da sociedade..." - OVERTON H. TAYLOR

O desenvolvimento econômico atingiło pelos Estados Unidos da América e por parte dos países da Europa Ocidental resultou, sem dúvida, do grande progresso tecnológico e do acúmulo de capitais occrridos no fins do Século XVIII e durante todo o Século XIX. Porém, não podemos subestimar no contexto de tal desenvolvimento o importante papel desempenhado pelo refinamento das técnicas de mercadização. Embora se possa objetar que no primeiro estágio o desenvolvimento de técnicas mercadológicas mais elaboradas tenha sido criado pela necessidade de escoamento de produção, resultante do alto desenvo:vimento tecnológico, com a conseqüente alta produtividade do capital e da mão-de-obra, por outro lado não se pode negar, aue, pelo menos nos úlimos vinte anos, as atividades mercadológicas têm influenciado a demanda, seja atingindo novas faixas até então situadas numa zona que poderíamos chamar de "subconsumo", seja criando novos

Aleerto de Oliveira Lima Filho - Professor-Assistente do Departamento de Mercadologia da Escola de Administração de Emprêsas de São Paulo, da Fundação Getúlio Vargas.

Carlos Osmar Bertero - Professcr-Assistente do Departamento de Administração-Geral e Relações Industriais da Escola de Administração de Emprösas de São Paulo, da Fundaçäo Getúlio Vargas. 
produtos que resultam da orientação para o mercado. Isso, pôsto, surge a chamada "sociedade afluente" como componente, em grande parte, de outro fenômeno antropológico-social a que daríamos o nome de "civilização mercadológica".

À medida que se atingiam no Ocidente níveis altíssimos de consumo, os pensadores passaram a cogitar dos possíveis efeitos que os novos padrões de vida poderiam vir a provocar para a cultura como um todo. O receio provinha do fato de que a pobreza fôra o quinhão partilhado por tôda a humanidade, deste longinquo passado histórico. Aliás, a falta de esperança de sair dêsse estado estêve implícita em todos até há pouco mais de um século.

Aceitamos, sem restrições, a tese de que grande parte da sobreestrutura social seja determinada pelo sistema econômico de uma sociedade. O que se vê, então, é que os sistemas morais, especialmente no que tiz respeito às chamadas "virtudes menores" (temperança, prudência, justiça), foram calcados num estágio de crescimento econômico em que a pobreza era a regra. Não estranha, pois, que os moralistas sempre se tenham inclinado para a focalização dos aspectos austeros e sóbrios da conđuta como sendo os moralmente corretos e, portanto, recomendáveis. Tal situação é de difícil aceitação numa sociedade afluente, onde tudo nos conduz a consumir e onde a virtude da poupanca acaba por perder qualquer sentido, a não ser como medida temporária para riqueza e consumo ainda maiores.

Dos atuais países desenvolvidos os EUA foi o que mais se defrontou com tal paradoxo. O pensamento lá dominante era, então, puritano, com base calvinista, onde poupança, austeridade, baixos padrões de consumo e reinvestimento máximo eram louvados como representativos de conduta moralmente adequada. Com o passar dos tempos, essa mesma sociedade foi forçada a adotar padrões de consumo em frontal desacôrdo com as normas éticas tradicionalmente pregadas e praticadas. $\mathrm{E}$ os pensadores se viram 
inclinados a emitir os mais sombrios prognósticos sôbre os "novos tempos".

Se bem que em outros perícdos da História os mesmos problemas tenham sido colocados, não cremos que o tenham sido com a mesma intensidade e a mesma extensão. No momento afloram-nos à memória o exemplo do mundo grego, ao compararmos os tempos da Idade Média Grega com o período helênico e helenístico, e o da vida romana, com um passado agrário rústico e sóbrio, e com o fausto, a riqueza e o refinamento da Roma Imperial. As transformações nessas duas culturas podem ser fàcilmente constatadas na literatura, nas artes plásticas, na evolução do ordenamento jurídico, na forma de organização familial e mesmo nos valôres éticos predominantes em cada uma delas. A mesma observação poderá ser feita, em período mais próximo aos nossos dias, quando assistimos à fragmentação do mundo medieval e ao aparecimento do mundo moderno sob o impacto do Humanismo e do Renascimento.

$O$ que podemos constatar nesses momentos em que a atividade econômica acarreta aumento dos níveis de consumo e mudança da estrutura social é uma fase de desajuste, em que os valôres éticos do passado ainda perduram, seguida por outra em que a nova estrutura vem determinar novos padróes éticos, adaptados à nova ordem de coisas. Exemplo disso poderia ser encontrado na célebre questão da usura e das suas conotações pecaminosas na moral medieval e em boa parte dos pensadores reformistas, e na sua posterior aceitação e transformação em valor èticamente positivo na fase de consolidação do capitalismo.

O que é singular em nossa época é que o desenvolvimento econômico, nos países em que ocoreu, propiciou a populações inteiras o acesso a níveis de consumo não encontráveis em nenhuma das épocas anteriores. A idéia do welfare state é típica do nosso século, pois nas nações ou impérios "ricos" do passado apenas uma pequena parte da população tinha acesso a padrões de consumo realmente 
elevados. E não resta a menor dúvida de que o esboroar dêsses impérios se deveu em boa parte a lutas internas de classes, levando a revoluções intestinas, causadas por profundos desequilíbrios estruturais na distribuição da renda.

Em nossos dias, nos países desenvolvidos, quando populações inteiras são alçadas à posição de "consumidores", esperam-se transformações muito maiores, porque a crise cultural e os valôres éticos estão sujeitos a substancial abalo e são suscetíveis de sofrer radicais reformulações. Algumas dessas reformulações já podem ser encontradas nessas sociedades, máxime no que diz respeito à estrutura familial. A família patriarcal, embora formalmente mantida, já foi substancialmente esvaziada, cedendo lugar a outros tipos de estrutura em que o patriarcalismo é eliminádo, seja pelo acesso feminino, seja pela transferência das funções paternas para a comunidade em geral. Nota-se, por outro lado, que os próprios mentores da vida religiosa cristã estão preocupados com "socializar" a caridade e a generosidade, a fim de que essas virtudes não se restrinjam ao círculo estreito das relações familiais e amistosas, mas se estendam à comunidade e ao mundo. No plano jurídico a preocupação com a salvaguarda do conceito de "soberania" - que obcecou o pensamento político dominante nos Séculos XVI, XVII e XVIII embora hoje ainda cultivada, fica $\mathrm{em}$ segundo plano se comparada à preocupação em conferir ao Estado o papel social de promotor do bem-estar de todos os cidadãos e de responsável primeiro e direto pelo desenvolvimento econômico e pela garantia de manutenção dos níveis já alcançados.

Aliás, o principal problema da sociedade afluente é exatamente $o$ da perpetuação da afluência. A preocupação com a expansão econômica constante (sustained growth) é uma forma de assegurar que a afluência obtida não seja u'a miragem que venha a dissipar-se. Pelo menos nos Estados Unidos da América e em alguns países da Europa Ocidental, as preocupações do economista deixaram de ser 
a escasse $z$ e a ameaça constante de desemprêgo e de colapso econômico, e passaram a colocar-se na ordem do crescimento constante e de pleno emprêgo.

Nesse contexto os problemas de produção e finanças passam a ter importância sensivelmente menor e a merecer menos atenção do que há algumas décadas atrás. É então que a esfera mercadológica passa a ser o fulcro da manutenção do ritmo econômico. Ela deixa de ser um simples apêndice da Economia para tornar-se autônoma como disciplina e tentar elaborar sua metodologia com padrões próprios.

A Mercadologia surgiu nos EUA sob a égide "funcional", em que os manuais e livros da década de 1930 sôbre a matéria a colocavam: consideravam-na a disciplina responsável pelo desempenho adequado de funções (compra, venda, transporte, armazenamento etc.). Já em fins de 1950 a Mercadologia passou a adotar uma dimensão administrativa (managerial) dos problemas da emprêsa. $\mathrm{E}$ assim vem sendo vista em nossos dias. Segundo a tese atualmente aceita, só por métodos mercadológicos é possivel determinar os potenciais de vendas e, a partir daí, estimar as necessidades de mão-de-obra, matérias-primas e financiamentos. Administrativamente falando, o orçamento de vendas é a peça fundamental para a programação das atividades da emprêsa e o elemento integrador dessas atividades.

Não se detém aqui, todavia, o desenvolvimento da Mercadologia em nossos dias. Outros problemas de cunho bem mais amplo e interdisciplinar preocupam o teórico, levando-o a recorrer ao concurso de outras disciplinas e a pedir a colaboração de especialistas em áreas ligadas às Ciências Sociais e às Humanidades. Exemplo típico dessa forma de preocupação é a problematicidade que pretendemos focalizar neste artigo. E é por isso que, ao levantar alguns dos problemas éticos suscitados pela afluência, marcadamente no que se refere às relações éticas da demanda, estamos compenetrados da idéia de que a atividade em- 
presária, mercadològicamente orientada, implica um sem número de fenômenos cuja seriedade para o homem transcende não só os limites da emprêsa, como os da própria economia.

OBJETIVO

Depois de definir a moral social, tal qual se apresenta numa sociedade "aquisitiva", ou seja, numa sociedade dominada por altos padróes de consumo, onde grande parte da atividade humana está voltada para o trabalho com a finalidade de adquirir bens e serviços, trataremos de alguns aspectos da demanda que apresentam especial interêsse para o desenvolvimento dos esforços mercadológicos.

Demonstraremos a maneira pela qual os consumidores reagem favorável ou desfavoràvelmente aos esforços mercadológicos das emprêsas e, ao mesmo tempo, explicaremos como os resultados finais dessas atitudes afetam a demanda e a economia como um todo.

Como base para essa discussão, faremos um breve retrospecto do que tem sido escrito sôbre o desempenho das emprêsas com relação aos seus consumidores. A essa altura entraremos numa área bastante controvertida, qual seja, aquela que analisa a propaganda, seus efeitos econômicos, sua influência sôbre o comportamento do consumidor e, finalmente, suas implicações éticas.

A proposição dos economistas nesse particular é bastante nítida e pode ser percebida em função de modelos, tais como os propostos por LeFTwICH, onde a propaganda não é mais do que outra forma de competição, que produz mais desperdício econômico do que seria desejável e, além disso, afeta de forma negativa o comportamento do consumidor. Outros modelos desenvolvidos por economistas poderiam ainda ser citados, como, por exemplo, a lei dos rendimentos decrescentes, a teoria da utilidade, os mapas de indiferença, que têm como ponto comum a negação da capacidade de o consumidor racioci- 
nar fora dos quadros lógicos do homo economicus. Discutiremos três autores que, embora de maneira diversa, com diferente formação cultural e de níveis intelectuais bastante distintos, se entregaram à crítica da atividade empresária moderna: ARNOLd TOYNBEE, VANCE PACKaRd e John K. Galbraith.

Elaboraremos, então, um modêlo mercadológico que servirá como base para a conclusão do artigo. $O$ tratamenic que daremos ao estudo da Etica não sera desenvolvido sob o prisma negativo e teórico de uma ética normativa, mas, ao contrárı, procurará enfatızar as implicações de certos padrões éticos sôbre a demanda e sôbre as atividades de mercadização.

Não nos propomos a elaborar uma nova Ética - não reivindicariamos tal pretensão -, mas simplesmente tentar apontar algumas soluções para uma situação de impasse: se, de um lado, a atividade empresária, na forma pela qual se conduz em nossos dias, é tachada de amoral, por outro, poucos duvidariam de que a expansão do consumo seja condição necessária, pelo menos nos países desenvolvidos, para a manutenção das taxas de crescimento e para evitar que a afluência ceda caminho, novamente, à depressão econômica e à pobreza.

\section{CONCEITOS E DEFINIÇÕES}

Ao nos afastarmos do modo de pensar daqueles que vêem na Ética uma seqüência normativa, dotada de valor porque metafisicamente fundamentada, e também da posição dos que, rejeitando embora fundamentação metafísica para os valôres éticos, buscam a fundamentação da ciência da moral na "reflexão moral", consideramos a moral como uma série de práticas, dotadas de valor "convencional", estabelecidas pela comunidade como medida para garantir a sua própria sobrevivência.

$\mathrm{Na}$ verdade, o problema só aparece, ao nível do homem social, como uma necessidade para o próprio relacionamento entre os membros da comunidade. Sob o aspecto 
da atividade econômica da comunidáde, reconhecemos que a necessidade de uma "moral dos negócios" se faz sentir (a) pela existência de um processo competitivo constante, que é elemento fundamental da atividade econômica da sociedade ocidental, formáda durante o período do liberalismo econômico, (b) pelo fato de nessa scciedade o desenvolvimento econômico ter gerado uma "sensibilidade" entre os seus membros que os tornou capazes de julgar as atividades empresárias, e (c) principalmente pelo fato de que tôda a ação em desacôrdo com a Ética dentro dessa comunidade empresária cria oportunidades para que o comportamento não ético se universalize, pondo em risco a própria sobrevivência da atividade econômica da comunidade.

O professor Eugene J. Kelley, da Universidade de Nova Iorque, acredita que as dimensões éticas da atividade mercadológica constituam elemento dinâmico bastante expressivo por se relacionar diretamente com o meio ambiente. A Mercadologia acaba por constituir-se no foco natural de tôdas as considerações éticas da atividade empresária porque é através da atividade mercadológica que a emprêsa. entra em contato com o consumidor e, conseqüentemente, com a comunidade no seu sentido mais amplo. ${ }^{1}$

Levando-se em crsnta que a atividade e o esfôrço mercadológicos estão ìntimamente relacionados com a demanda, os nossos valôres básicos relativos à atividade mercadológica podem ser utilizados para reaiizar um estudo da demanda sob o prisma ético. Em outras palavras: tôda a ação que se realize na área da mercadização deve levar em conta tôdas as consequiências possíveis dessa ação sôbre a demanda.

Se é verdade que a Ética se consubstancia numa série de valôres, dotados de caráter relativo tanto no espaço como no tempo, segue-se que as convenções éticas mudam de sociedade para sociedade e até mesmo dentro de u'a mes-

1) Kelley e LAZER, Mana gerial Marketing, Homewood, Ilinóis: Richard $D$. Irwin, 1962, pág. 49. 
ma sociedade em determinado lapso. O que é positivamente sancionado tem implìcitamente o caráter de ação correta porque verdadeira e boa. O comportamento humano é penetrado pelas convenções éticas do grupo e permeia tôda a gama da atividade humana grupal e individual. Dessa forma a eticidade da conduta humana tende a refletir-se em atitudes profissionais que servem como quadro de referência para a sociedade em que estão localizadas. Qualquer pessoa relacionada com a atividade mercadológica, seja nas áreas teóricas da pesquisa ou dos estudos em nível universitário, seja no campo da prática administrativa, deverá manter um padrão profissional compatível com o padrão ético vigente na sociedade em questão. A honestidade e a autenticidade constituem parte importante da ética profissional, não porque se trate apenas de uma questão de aceitação ou rejeição de padrões sociais, ou porque se trate de seguir um conjunto de regras que sejam dotadas de validade, mas porque, em última instância, o objetivo final de uma atividade profissional conduzida èticamente acaba por impor-se como condição de sobrevivência.

Thomas GarRetT, no seu livro Ethics in Business, afirma que o indivíduo não pode responsabilizar-se pelo que se encontra fora de seu contrôle ou pelos fatôres que não podem ser por êle alterados. ${ }^{2}$ Assim sendo, em determi= nada fase do processo decisório não podemos mudar nossas atitudes na conduta dos negócios, nem tampouco esquecer nossas relações com a sociedade.

A fim de compreender essas definições, que são básicas, devemos atentar para o fato de que, de acôrdo com a proposição de STAUDT, o mercado e o consumidor retêm para si a fôrça de veto (veto power), sôbre todo o sistema mercadológico. Isso nos permite adotar uma posição segundo a qual diminui a margem de contrôle que as emprêsas exercem sôbre a demanda através do uso de artifícios des-

2) Thomas M. GaRretT, Ethics in Business, Nova Iorque: Sheed, Wand, Inc, 1963 , pág. 48. 
tinados a alterar a motivação, chegando-se, num estágio posterior, em que a sociedade atinge um nivel mais elevado de desenvolvimento e conhecimento, a uma reação bastante agressiva e negativa por parte dos consumidores a quaisquer ações não éticas ou não racionais.

Podemos afirmar, em última análise, que as dimensões éticas da Mercadologia devem ser dirigidas em direção a alto grau de coerência com os objetivos da emprêsa e da sociedade como um todo integrado.

\section{DEMANDA E MERCADOLOGIA}

Os administradores mercadológicos devem preocupar-se com as possíveis determinantes da demanda - o porque e o como o comprador responde aos esforços feitos no sentido de convencê-lo - com as expectativas do consumidor em relação aos produtos, com o que êste espera das emprêsas no que diz respeito a atitudes e confiança nas informações recebidas e, finalmente, com o grau de autenticidade das mensagens e das comunicações entre a emprêsa e os seus compradores.

Sabemos que com a utilização das técnicas modernas de pesquisa as emprêsas podem prever, dentro de certos limites, o comportamento do comprador, bem como a quantidade de vendas que obterão num período futuro ou em determinado mercado. Além disso, entretanto, podemos verificar que essas previsões são sèriamente limitadas por fatôres externos não controláveis, dentre os quais podemos citar a ação competitiva de outras emprêsas.

Entretanto, além do simples fato de alcançar um objetivo de venda predeterminaldo, podemos afirmar que existem outras considerações no que tange ao contrôle e à manipulação da demanda. Em tal situação, qual seria o julgamento dos clientes com relação aos padrões éticos da emprêsa em questão? Quando esta usa determinados artifícios de venda e de propaganda, estaria ela realmente servindo aos objetivos e necessidades reais do mercado? $\mathrm{Te}$ ria a sua influência sôbre a demanda sido ética e racional? 
Como é sabido, a demanda pode ser afetada pela propaganda e por fatôres controláveis pela emprêsa. Por outro lado, a demanda pode também estar sujeita a custos mercadológicos, preços e outros elementos do sistema de mercadização. Melhorias no produto devem ser intrciduzidas com a finalidade de expandir a demanda, mas muitos compradores nem sequer têm noção do que sejam "qualidades ocultas", isto é certas caraterísticas e dimensões funcionais do produto que não podem ser percebidas ao primeiro contato. Assim sendo, o objetivo da propaganda é tornar possível uma associação mental entre as qualidades dos produtos $\mathrm{e}$ as suas respectivas marcas. A honestidade e a autenticidade dessas mensagens é questão de ética e de moralidade por parte dos comerciantes que as controlam.

No conceito dos economistas clássicos as vendas eram simples função inversa dos preços. Mais tarde, essa função foi expressa em têrmos do que se conhece como lei da procura e que resume as relações preço/venda. " $\mathbf{E}$ importante mencionar que a Mercadologia, utilizando-se de vários artifícios e instrumentos de análise que lhe foram fornecidos por outras disciplinas, inclusive pelas chamadas "ciências do comportamento", foi capaz de colocar a demanda sob "parcial contrôle", função que para os economistas clássicos se apresentava como um mecanismo rìgidamente determinado pelos demais elementos componentes do universo econômico, tal qual era êste concebido pelo pensamento então dominante. ${ }^{4}$

3) Alfred R. Oxenfeldt, Managerial Marketing, Homewood, Ilinóis: Richard D. Inwin, 1962, pág. 42.

4) "A racionalidade do ser humano, para o economista, implica em que êle preferirá sempre tomar as decisões econômicas que tornem maior o seu prazer e que lhe custem o menor esfôrço possível. Assim, como consumidor, êle escolherá sempre o mais barato entre dois produtos inteiramente idênticos e o que lhe dê maior satisfação entre dois preços iguais. Entre dois produtos diferentes e com preços desiguais o consumidor dará preferência àquele em relação ao qual sej̣a maior a diferença entre a satisfação de possuí-lo e a insatisfação de pagar o seu preço. Da mesma forma, como produtor, vendedor ou empreendedor, o ser humano tenderá a preferir sempre a alternativa que torne máxima a diferença entre a satisfação auferida com a venda de seus produtos e a insatisfação provocada por sua obtenção ou produção. Daí dizer-se, pela ex- 
Conseqüentemente, é sabido em nossos dias que as condições do mercado são extremamente diferentes das descritas pelos economistas clássicos e que grande quantidade de novos fatôres altera e modifica a escala da demanda. Assim sendo, os estudiosos e administradores práticos que estão envolvidos na execução das atividades mercadológicas das emprêsas devem estar atentos quanto a êsses fatôres para tratar o problema da expansão da demanda não só em têrmos de preços, mas também levando em consideração os problemas da cultura em que a emprêsa atue, inclusive no tocante aos padrões éticos, quando se trate de integrar recursos administrativos para competir num determinado mercado.

ÉTICA E CONSUMO

Se, porém, a emprêsa puder usar artifícios que se afastem dos padrões éticos normalmente aceitos por prazo de tempo curto, e dessa forma conseguir manter-se no mercado, mesmo quando seus produtos e serviços não sejam da qualidade que seria de desejar, é certo que, decorrido maior lapso, a reação desfavorável dos consumidores se fará sentir. Em virtude disso, os concorrentes podem utilizar-se de instrumentos de propaganda e de comunicações que lhes possibilitem informar o mercado a respeito de tôdas as qualidades e vantagens de seus produtos, em oposição às informações incorretas da emprêsa aqui considerada. Como consequiência, a médio e a longo prazos as reações dos consumidores tornar-se-ão efetivas e as vendas dessa emprêsa que opera fora dos padrões normalmente aceitos principiarão a declinar.

Cremos também que numa economia desenvolvida, onde haja abundância de bens e serviços e onde a renda disponível seja elevada e eqüitativamente distribuída entre a

pressão da primeira em receita e da segunda em custos, que o empreendedor procura tornar máximos os seus lucros." - GUSTAVo DE SÁ E SIIVA, Compêndio de Administração Mercadológica, a ser publicado pela Fundlação Getúlio Vargas, capítulo sôbre "Determinação de Preços", pág. 4. 
população, acabe por estabelecer-se uma tendência para a racionalização e a sofisticação do consumo.

O consumidor, tendo acesso a um número muito grande de locais de compra e com possibilidade de escolher entre grande número de produtos, não admite a possibilidade de ser objeto de enganos em sua atividade de compra. Nesse caso a situação do consumidor frustrado coloca-o numa posição em que êle se torna fonte de informações negativas no que diz respeito à emprêsa e aos produtos por ela produzidos.

Ainda dentro dêsse conceito, podemos afirmar que os executivos não devem padronizar suas ações apenas dentro dos limites da lei ou dos regulamentos. Êles têm de levar em consideração, também, as implicações sôbre o bem-estar econômico-social, que será a conseqüência de suas ações administrativas. De muitas maneiras recebe o consumidor informações sôbre o mercado, sôbre os produtos e sôbre os vendedores. Essas informações e suas respectivas fontes são pràticamente ilimitadas. ${ }^{`}$ Sabe-se, também, que a reação dos consumidores criou, em alguns casos, sociedades com o objetivo principal de proteger suas economias e fornecer dados sôbre a atitude geral das emprêsas no trato de seus clientes. ${ }^{6}$

Em nosso meio podemos citar o fato de que as associações de classe e aquelas do tipo do Movimento de Arregimentação feminina (MAF) alertam os seus associados a respeito dos padrões éticos das emprêsas fornecedoras de produtos de consumo ou de bens industriais.

O consumidor mais avisado pode tornar difícil a ação administrativa dos vendedores menos preocupados com questões de Ética. Pode, além disso, comprar daqueles que a priori tentaram, através de suas ofertas no mercado,

5) JoHN A. HowARD, Marketing Management, Homewood, Ilinóis: Richard D. IRWIN, 1963, pág. 388.

6) Èsses serviços são explicados por Eugene BEEM e JoHn S. EwING no artigo "Business Appraises Consumer Testing Agencies", da Harvard Business Review, Vol. XXXII, n. 2, 1954. 
oferecer produtos realmente compatíveis com as suas necessidades. $^{7}$

Todos êsses fatos são indicativos de que o consumidor tem aberto para si novos horizontes em têrmos de direitos e podêres econômicos, em relação à posição outrora ocupada pelos vendedores.

\section{CRÍTICA À ATIVIDADE EMPRESÁRIA}

É natural que em qualquer grupo ou sociedade humana onde um pequeno segmento atinja posição de proeminência haja crítica e pressão sociais dirigidas contra êsse segmento da sociedade.

Embora no passado as emprêsas freqüentemente tenham deixado de seguir muitos dos princípios hoje vigentes na prática dos negócios, principalmente no que diz respeito à qualidade do produto e à focalização de suas atividades sôbre a figura do consumidor, em nossos dias, especialmente nos países desenvolvidos, o progresso dessa mesma atividade empresária acabou por forçar as emprêsas a dedicarem mais atenção ao consumidor. Atualmente a crítica à atividade empresária dirige-se contra as atividades de mercadização e, mais especificamente, contra os elementos do "composto promocional", no sentido de que a mercadização tenderia a conferir ao consumo um caráter não ético, violentando a liberdade do consumidor e manipulando sua capacidade de escolha e decisão para levá-lo a consumir os produtos que as emprêsas querem sejam consumidos. Tal crítica constitui o leit-motive dos livros de VANCE PaCKard e, num nível indiscutivelmente mais alto, de TOYNBEE, que vêem na procura desenfreada de bens de consumo, a que induzem os esforços promocionais dalas emprêsas, uma forma de desperdício de energias e recursos humanos que poderiam ser encaminhados na busca e consecução de objetivos mais elevados. Claro está, a crítica de Toynbee, Fromm e outras pessoas que se

7) VANCE Packard, The Hidden Persuaders, Nova Iorque: Pocket Books, Inc., 1963, pág. 223. 
colocam na mesma perspectiva, baseia-se em valôres éticos estranhos à problematicidade econômica e que necessitariam ser reavaliados em face da nova fenomenologia econômica dos países desenvolvidos, mormente dos Estados Unidos da América.

Além de PACKARD e ToYnbee, acrescentaríamos à nossa lista de críticos JoHn K. Galbraith e, a fim de tornar nossa análise mais metódica e objetiva, passaremos a expor e criticar o pensamento de cada um dos autores.

- VANCE PACKARD, autor de livros bastante agressivos quanto às ações da mercadização sôbre a demanda, é talvez o crítico mais conhecido no Brasil e nos EUA. Suas obras foram muito divulgadas e o seu estilo jornalístico e vivo torna a leitura sobremaneira agradável e as suas idéias fàcilmente inteligiveis. Dentre seus livros destacam-se: The Hidden Persuaders (traduzido em português sob o título "A Arte de Convencer"), The Status Seekers e The Waste Makers.

PACKARD critica a sociedade capitalista norte-americana e também o mundo ocidental como objeto das ambições desmedidas das emprêsas. Ao mesmo tempo, afirma que essas sociedades foram conquistadas por "persuasores ocultos", classificando-as de "economias de desperdício", nas quais o povo adquire mais do que o necessário. Menciona dois fatôres que considera de extrema gravidade para o neocapitalismo: (a) o de haver completa sujeição do comprador aos efeitos da propaganda e (b) o de a produção atualmente demonstrar baixo padrão de qualidade por estarem os vendedores desejosos, tão-sòmente, de vender grandes quantidades, motivo por que teriam passado a introduzir fatôres de obsoletismo planejado, fazendo com que a utilidade do produto se deteriore ràpidamente, a fim de que haja novas oportunidades de venda.

VANCE PACKard inicia seu livro The Waste Makers com uma descrição do que êle considera "A Cidade do Futuro" (Cornucópia), na qual todos os prédios seriam feitos de um papel especial a fim de que fôssem remodelados em 
cada primavera ou outono. ${ }^{8}$ Os carros dessa cidade seriam fabricados de um plástico bastante leve, que desenvolveria a fadiga e começaria a fundir-se depois de o automóvel rodar mais de 6.000 quilômetros. ${ }^{9}$

PACKARD conhece bastante as operações e os produtos das companhias americanas, o que faz com que muitos dos seus exemplos pareçam corretos e conclusivos à primeira vista. Entretanto, suas afirmativas não resistem a uma análise mais detida. Para êle a "pesquisa motivacional" tem como único objetivo o domínio do consumidor. Êste, segundo PACKARD é, "em princípio", ignorante e impulsivo no seu comportamento de compra. Para o autor as agências de propaganda e as emprêsas manufatureiras e fornecedoras đe serviços estão imbuídas de fundamental "má-fé" e não vêem outro objetivo a não ser o lucro. Chega a afirmar que o consumidor norte-americano compra 50\% a mais do que realmente necessita, e que os responsáveis por tal desperdício são aquêles que estão transförmando os sêres humanos em criaturas cada vez mais pródigas, com necessidades de consumo superiores ao que naturalmente se deveria esperar dos sêres humanos. ${ }^{10}$ As emprêsas usariam nove estratégias básicas a fim de aumentar o consumo, dentre as quais o espírito de desperdício, o obsoletismo planejado e a dificuldade no reparo e na manutenção dos novos produtos.

A nosso ver, PACKARD adotou uma posição extremada, chegando à conclusão de que todos os consumidores são dotados de mentalidade infantil e que, além disso, não existindo leis e regulamentos, as atividades econômicas se tornariam absolutamente "livres", e tudo seria fàcilmente aceito.

Entretanto, não é isso o que ocorre na realidade. Além disso, segundo o autor, as emprêsas poderiam fazer o que quisessem, sem restrição, e os competidores seriam abso-

8) VANCE PACKARD, The Waste Makers, Nova Iorque: Pocket Books, Inc., 1963, pág. 3.

9) Idèm, ibidem, pág. 4

10) Iđem, ibidem, pág. 28. 
lutamente inoperantes. PACKARD esquece que os reflexos econômicos do ambiente por êle imaginado levariam a economia de um país a um colapso total dentro de pouco tempo.

Em oposição à "Cornucópia", pode-se imaginar outra cidade do futuro, que chamaríamos de "Ferro Velho" ou "Poeirenta", onde haveria carros com tais aperfeiçoamentos técnicos que permitissem velocidades máximas de apenas 30 quilômetros horários... (Note-se que o escritor apresenta uma posição extremamente conservadora relação às inovações técnicas.)

- O segundo autor que critica a atual posição das emprêsas capitalistas e as suas operações de mercadização é ARNOLD TOYNBEE, historiador inglês que, proferindo uma conferência em Williamsburg, na Virgínia, em 1961, fêz inúmeras restrições às atitudes e práticas capitalistas de negócios, principalmente no que se relaciona com os aspectos éticos e religiosos do problema. Um ponto básico de seu pronunciamento é transcrito a seguir: "No Hemisfério Ocidental, nos dias de hoje, o papel da tentação é desempenhado por tudo aquilo que costumamos resumir sob o nome de Madison Avenue. Parte considerável de nossas habilidades, energia e tempo material está sendo aplicada para induzir-nos a encontrar dinheiro a fim de comprar bens que nunca imaginaríamos possuir..." 11

De acôrdo com ToynbeE, a atividade propagandística também não é econômicamente justificável: "Uma economia que depende, para sua sobrevivência, de estímulos artificiais de desejos materiais parece estar fadada a não sobreviver por muito tempo ${ }^{12 \%}$.

As críticas de ToynBEe são antiquadas, principalmente porque êsse autor parece não reconhecer o estágio de progresso alcançado pelos Estados Unidos da América e por certas áreas nas quais o desenvolvimento econômico atin-

\footnotetext{
11) ARNold J. ToYnbee, The Continuing Effect of American Revolution, conferência em Williamsburg, Virgínia, junho de 1961.

12) TOYNBEE, op. cit.
} 
giu grau mais avançado. Ora, como se sabe, o consumo é o principal responsável pela riqueza e pelo progresso das nações capitalistas. Todo o sistema capitalista está baseado em premissas segundo as quais o bem-estar econômico deve ser atingido. Alguns traços - chamados por ToynBEE de "materialistas" - da sociedade moderna não poderiam ser modificados, pelo menos num breve espaço de tempo. De qualquer modo, não nos aventuraremos no arriscado terreno da profecia, mas acreditamos que a avidez por bens materiais é um dos traços caraterísticos do nosso tempo, e uma humanidade que busca, por todos os meios, o aumento de sua riqueza econômica terá de preterir, inevitàvelmente, a busca de outros objetivos.

Não sabemos se algum dia a humanidade voltará a buscar os mesmos elementos "espirituais" de que nos fala ToynbeE. Mas, o que julgamos inevitável é a mudança dos padrões éticos de uma sociedade voltada para o desenvolvimento econômico e que abandonou os valôres que enfatizavam outros elementos. Sabemos que no plano teórico não existe conflito entre a consecução dos objetivos do desenvolvimento e a dos objetivos chamados "espirituais", mas por enquanto não se conhece exemplo de nenhuma sociedade que, tendo entrado pela senda da busca do acúmulo de bens econômicos, tenha, ao mesmo tempo, mantido o mesmo empenho na busca de bens não mensuráveis econômicamente. $\mathrm{O}$ que a História nos indica é que a procura do desenvolvimento tem funcionado como elemento catalizador de tôdas as energias humanas. E, se opção tivesse de ser feita, in extremis, entre a realização econômica e o que TOYNBEE chamaria de "realização espiritual", não há dúvida de que a escolha recairia na primeira alternativa. Ao enveredar pela senda do desenvolvimento e ao adquirir bens e serviços que criam uma sociedade com hábitos e valôres bastante diversos dos existentes há séculos, não cremos estejamos agindo imoralmente; estamo-nos apenas dirigindo para outros caminhos, com a consequiente reformulação dos padrões éticos vigèntes. De que tal movimento implique riscos, não há a menor 
dúvida. A humanidade, porém, sempre abandonou sistemas éticos e religiosos consolidados para adotar outros, e o risco é inerente a tôda a atividade humana.

Acreditamos que, se reduzíssemos a aplicação de recursos e esforços tendentes a aumentar os níveis de consumo, tal atitude poderia conduzir a economia a uma posição de estagnação, que seria extremamente perigosa e oposta aos objetivos do desenvolvimento econômico. Evidentemente, no estágio de desenvolvimento em que se encontra o Brasil torna-se necessário o atendimento dos desejos primários de consumo, com restrição do "consumo supérfluo". Entretanto, êsse complexo situacional não invalida a tese de que o consumo precise ser incentivado, e de que sòmente atingiremos fases mais avançadas de desenvolvimento econômico quando tivermos eliminado as áreas de subconsumo. Dessa maneira, podemos notar que a atividade mercadológica, orientada para a expansão do consumo e a elevação dos níveis de renda, encontra, a nosso ver, apoio ético e racional quando analisada pragmàticamente.

- Outro autor que gostaríamos de comentar é JoHN K. Galbraith, autor do já clássico The Affluent Society. Dentre os três autores cujas teses nos propusemos a analisar no decorrer dêste artigo, GALBRAITH parece-nos o que apresenta mais sólida argumentação contra os perigos de uma "economia de consumidores". Êle não se detém na análise do que possa ser èticamente necessário ou desnecessário, correto ou incorreto, no exercício da atividade econômica. Preocupa-se, simplesmente, com os efeitos a longo prazo, para a segurança nacional e para a sobrevivência de uma nação, ou de um grupo de nações - de uma economia bàsicamente orientada em direção aos bens de consumo.

Não há dúvida de que tudo poderá ser objeto de crítica na economia norte-americana, menos a satisfação do consumidor. $\mathbf{E}$ a satisfação do consumidor foi realizada graças ao desenvolvimento das atividades de mercadização e pela orientação "mercadológica" tas emprêsas norte-america- 
nas. Porém, quando em 1957 a URSS lançou o primeiro satélite artificial da terra ao espaço GALBRAITH comentou irônicamente que o único grande feito norte-americano fôra o lançamento de uma linha "revolucionária" de automóveis, dentre os quais apenas o "Edsel" da Ford fôra estèticamente aceito pelo mercado. Em 1957 a lacuna entre o produto nacional bruto soviético e o norte-americano davam ampla margem de tranqüilidade para os observadores norte-americanos acreditarem que tal proeza espacial não poderia ser realizada pelos soviéticos porque o seu PNB ainda era muito pequeno. Porém, a "arrancada" espacial soviética mostrou que a concentração de esforços permitiu uma façanha sem precedentes, a despeito de uma menor riqueza nacional.

Segundo GaLBRAITH, é necessário controlar os esforços de uma economia dirigida exclusivamente para o consumidor. Relembra-nos o autor que as emprêsas nada fizeram pelo desenvolvimento da energia atômica, pelo simples fato de que a sua aplicação comercial era e ainda é dotada de muito poucas perspectivas de lucro. A General Motors sempre se interessou àvidamente por tudo o que diz respeito a transporte nos mares, na terra e no ar. A despeito disso, a grande emprêsa nunca empregou seus amplos recursos de "pesquisa e desenvolvimento" para cuidar do transporte espacial.

Em conclusão, diz GALBRAITH que uma economia voltada fundamentalmente para o consumidor correria o risco de estagnação tecnológica, porque a produção e a produtividade deixariam de constituir o fulcro das preocupações econômicas. ${ }^{13}$

Dentre os três autores analisados acreditamos ser GALBRAITH o que apresenta os argumentos mais impessoais e mais técnicos com relação a atitudes não racionais das economias de mercado, sem todavia tratar do problema da eticidade dessas atividades econômicas.

13) John K. Galbraith, The Affluent Society, Nova Iorque: Mentor Book, 1963, pág. 119. 
Concordamos com êle quando afirma que uma economia que orientasse os seus recursos puramente em direção à satisfação do consumo correria o risco de criar grupos cada vez mais ricos, que se apoiariam na pobreza e na fome de bilhões de sêres humanos.

\section{MODÊLO PROPOSTO}

As análises que têm sido usadas pelos homens de emprêsa para avaliar seus próprios padrões éticos e suas atividades têm sido falhas. Não utilizaram êsses empresários os conhecimentos mais avançados dos economistas, dos teóricos de Administração e dos demais cientistas sociais para formar um quadro básico de referência destinado a avaliar seus conceitos e seus desempenhos.

Por essa razão, nossa discussão tenta explicar os dilemas dêsse campo controvertido dos estudos mercadológicos.

Pensamos, entretanto, que a discussão a respeito dêsse problema possa tornar-se mais clara e revestir-se de caráter mais prático se introduzirmos um modêlo que procure esquematizar as ações das emprêsas no sentido de julgar a oportunidade mercadológica, a fôrça de competição e a necessidade de tornar suas ofertas compativeis com os desejos e os padrões do consumidor. Por outro lado, procuramos visualizar o consumidor e seus problemas quando age no mercado.

Com essa intenção desenvolvemos um modêlo básico (v. Figura Única), que procura demonstrar como os aspectos básicos e éticos da demanda são produto da interação entre a emprêsa e seus clientes. Nesse modêlo podemos delinear duas regiões principais:

A) $\mathrm{Na}$ "esquerda baixa" do modêlo colocamos a emprêsa e seus esforços administrativos, seu composto de produtos e serviços, e os ajustamentos à competição; todos êsses fatôres podem ser analisados não só em têrmos mercadológicos, mas também em função dos princípios e das atitudes éticas da emprêsa. Todos êsses tópicos são colo- 
cados na área inferior à curva de demanda, fato êsse que procura visualizar a caraterística segundo a qual nesse contexto a emprêsa se esteja confrontando com fatôres controláveis e não controláveis. Considerariamos fatôres controláveis pela emprêsa o produto, o local e os preços; fatôres não controláveis seriam as inovações por parte dos competidores, o esfôrço promocional dos competidores, as modificações introduzidas na estrutura de distribuição, a modificação do ordenamento jurídico e o aumento dos custos dos fatôres de produção.

B) $\mathrm{Na}$ "direita alta" colocamos o consumidor e suas ações no mercado durante três estágios que consideramos relevantes, ou seja, o estágio de preaquisição, o estágio de escolha e o estágio de compra. Em tôda essa área o consumidor pode realizar julgamentos e ações que estão sob o seu contrôle. Entre o domínio do consumidor e a área de atividade das emprêsas colocamos as expectativas de atitudes do consumidor quanto aos padrões éticos das emprêsas.

Êsse modêlo, que tem caraterísticas precisas quanto à sua dinâmica, não padece, a nosso ver, de falhas no que diz respeito à abstração necessária a êsse instrumento de análise, porque constitui representação bastante aproximada das ações das emprêsas e do consumidor ao longo da função de demanda.

UTILIZAÇÃo RACIONAL DA FÔRÇA DE MERCADIZAÇÃo

Acreditamos que na hierarquia de valôres de nossa cultura ocidental o ético e o racional se coadunem. Acreditamos, outrossim, que as emprêsas podem abordar problemas competitivos com relação à demanda como fatos reais da maior importância, porque nesse contexto estão lidando com problemas de sua sobrevivência e do bem-estar social.

A posição tomada pelas emprêsas no que diz respeito aos problemas éticos da demanda pode ser fàcilmente colocada em bases racionais, desde que se aceite o pressuposto, apon- 
tado acima, de que qualquer atitude não ética será tambem não racional. Portanto, aquêles que vendem não podem assumir atitudes de extrema avidez sem correr o risco de quem age fora dos quadros da racionalidade inerente à atividade econômica. As emprêsas também não podem pensar que os reflexos e os malefícios de suas atividades não éticas sejam dirigidos sòmente ao público, pois a emprêsa e a sociedade não podem ser separadas, uma vez que as operações econômicas são sempre resultado último da interação com um público que só mantém sua capacidade de compra quando as emprêsas, mediante atitudes adequadas, mantêm a distribuição eqüitativa de seus recursos e do seu capital.

Não podemos entender uma economia em fase de desenvolvimento sem propaganda, sem a reposição de produtos velhos por novos, mas também não podemos aceitar que a competição permita atividades não éticas por parte de um pequeno número de emprêsas. Não é racional, da mesma forma, forçar o consumidor a agir como autômato e supor que êle possa ser controlado à distância através do esfôrço promocional. Tal atitude careceria de coerência e seria não ética.

A propaganda pode ser utilizada de forma racional, como meio de informação, como fôrça de aceleração do ciclo econômico e como fator destinado a inter-relacionar e melhorar os critérios básicos de escolha. Nessa mesma linha de raciocínio, as atitudes e o comportamento das emprêsas, em meio a um regime capitalista, podem ser dirigidas ao objetivo comum do bem-estar social resultante do desenvolvimento econômico.

No sistema capitalista a responsabilidade primordial de qualquer emprêsa é operar com lucros. Logo a seguir, surge a necessidade de crescimento. A emprêsa é o órgão criador e produtor de riquezas da sociedade. ${ }^{14} \mathrm{Um}$ dos grandes desafios à atividade mercadológica é manter os

14) Peter DRUCKer, The Practice of Management, Nova Iorque: Harper and Brothers, 1954, pág. 17. 
recursos criadores de riquezas intatos e realizar lucros, sem colocar em risco a atividade econômica e o bem-estar social. Se as emprêsas adotarem atitudes não éticas, elas estarão agindo de forma não racional, pois o seu crescimento e o desenvolvimento econômicos estarão prejudicados. Embora o conflito entre interêsses particulares e públicos seja ainda uma constante no conflito do comportamento humano, as atividades de mercadização devem ser analisadas e realizadas de modo que autênticamente satisfaçam a demanila do mercado, a custos baixos, com aumento da qualidade e com objetivos de desenvolvimento econômico por prazo indeterminado.

Hoje a racionalidade no desempenho mercadológico é condição de sobrevivência da emprêsa e fator constante de uma economia que se destine a satisfazer as necessidades do homem, e nesse campo não se toleram posições não éticas.

Acreditamos que o mercado brasileiro, há cêrca de dois anos, tende a adotar um comportamento mais ético, porque mais racional, simplesmente porque o avanço tecnológico, a competição e a habilidade no analisar o que é correto e o que é incorreto estão aumentando em nossos mercados. $O$ velho comerciante ladino e oportunista será substituído por experientes homens de mercado e assessôres econômicos. Essa tendência far-se-á notar principalmente no que diz respeito à filosofia do lucro, que acentuará as necessidades de mercadização em massa com redução de custos e menores margens de lucro.

Como já afirmamos, a administração mercadológica trata especificamente das influências e dos fatôres que alteram as caraterísticas da demanda, a qual, por sua vez, reflete o julgamento dos consumidores. Nada nos pode convencer de que o consumidor brasileiro haja de aceitar, por período muito longo, atividades mercadológicas não conformes à Ética e que a nossa economia possa desenvolver-se sem que se adotem atitudes éticas e racionais no trato dos processos de venda e distribuição. 